\title{
Concurrent Infection of Trichuris ovis and Eimeria ninakohlyakimovae in Goat: A Case Report
}

\author{
M. Chelkar ${ }^{1}$, S. Panda ${ }^{1}$, M. S. Hedau ${ }^{1 *}$, N. V. Kurkure ${ }^{1}$ and S.W. Kolte ${ }^{2}$ \\ ${ }^{1}$ Department of Veterinary Pathology, ${ }^{2}$ Department of Veterinary Parasitology, Nagpur \\ Veterinary College, Maharashtra Animal and Fishery Sciences University, Nagpur, India \\ *Corresponding author
}

\section{A B S T R A C T}

\begin{tabular}{l} 
K e y w o r d s \\
$\begin{array}{l}\text { Eimeria } \\
\text { ninakohlyakimovae, } \\
\text { Goat, } \\
\text { Histopathology, } \\
\text { Morphometric } \\
\text { analysis Trichuris } \\
\text { ovis }\end{array}$ \\
$\begin{array}{l}\text { Article Info } \\
\text { Accepted: } \\
14 \text { November } 2020 \\
\text { Available Online: } \\
10 \text { December } 2020\end{array}$ \\
\hline
\end{tabular}

Keywords

Eimeria

Goat,

Histopathology,

Morphometric

analysis Trichuris

Article Info

Accepted:

Available Online:

December 2020
The present study reports a case of co-infection with Eimeria ninakohlyakimovae and Trichuris ovis in goat kid. Clinical history demonstrated severe illness withanorexia, increased lethargy and greenish yellow diarrhoea. Necropsy examination demonstrated thickened and congested intestinal mucosa. Non-pedunculated whitish nodules were seen on the mucosa of jejunum and ileum. Trichurisovis worms were embedded in the caecal mucosa by their anterior end. The intestinal contents revealed numerous coccidian oocystsof Eimeria ninakohlyakimovae. Eosinophilic nuclei with centrally placed nucleus in macrogamonts and basophilic nuclei in microgamonts were arranged in periphery with infiltration of lymphocytes and few plasma cells in intestine. Characteristic lesions observed were hyperplasia of intestinal epithelium and villus blunting.

\section{Introduction}

Coccidiosis is a major stress induced enteric protozoan disease causing severe losses to livestock industry. It is caused by microscopic Apicomplexon organism called Coccidia. A total of 17 Eimeria species have been described in goats. Coccidiosis in animals mainly depends on factors like age of animal, species of Eimeria, number of oocysts ingested and managemental practices. Eimeria in goats develops in small and large intestine and causes enteritis eventually resulting in death of the infected animal. Eimeria ninakohlyakimovae has been frequently associated with caprinecoccidiosis worldwide and is also regarded as pathogenic for animals of all age groups (Kanyari, 1993). Analogous to the bovine system, where the most pathogenic Eimeria species infect epithelial cells and develop into macromeronts, Eimeria ninakohlyakimovae also resides in this peculiar location and shows similar developmental features (Ruiz et 
al., 2006) leading to severe intestinal disease characterized by catarrhal diarrhoea, weight loss, dehydration and stunted growth (Koudela and Boková,1998). Eimeria parasite in goat can be located in liver, gall bladder, hepatic and mesenteric lymph nodes and small and large intestine (Nourani et al., 2006).

Trichuris ovis is a commonly occurring round worm found in caecum of the hosts. The anterior end of the worm forms syncytial tunnels of epithelial cells around itself while it burrows through the host mucosa (Grencis and Laura, 2004). The posterior end protrudes into the lumen facilitating egg release. Heavy infection is usually observed in kids suffering from diphtheritic caecitis causing necrotic lesions on mucosa (Soulsby, 1982). This is the report to document mixed parasitic infection of Trichuris ovis and Eimeria ninakohlyakimovae in a goat.

A 17 day old, goat kid was received for necropsy with a history of anorexia, depressed growth rate, dullness and severe diarrhea. The clinical material was collected from goat kid at the time of postmortem at Department of Pathology, Nagpur Veterinary College, Nagpur, India. A detailed post mortem was conducted and intestinal content was collected for direct smear method and standard floatation technique. Sporulation of the separated oocysts was performed in wet chamber at $24-26^{\circ} \mathrm{C}$ in a $2.5 \%$ aqueous solution of potassium dichromate (You, 2014). Tissue samples of intestine were collected in $10 \%$ buffered formalin for histopathological study. The formalin-fixed tissues were subjected to histopathological processing as per standard procedures (Luna, 1968). The worms recovered from the caecal mucosa were collected, washed and stretched in normal hot saline. The worms were preserved in $70 \%$ alcohol, dehydrated in glycerine-alcohol and then placed in desiccator at room temperature for 3-4 weeks for clearing. Dehydrated nematodes were then mounted on glass slides in anhydrous glycerine and observed under the microscope (Zainaband Wajihullah, 2016).

Grossly, the intestinal mucosa showed congestion and thickening. Direct smear and standard floatation technique of the intestinal contents revealed coccidian oocysts. The coccidian oocysts were identified on basis of its morphological features like shape of oocyst, presence of micropyle, polar cap, colour, shape of sporocyst and presence of stieda body (Soulsby, 1982). Results of the present study revealed that oocyst were sub spherical with micropyle. Micropylar cap was absent. The oocyst wall was double layered and $2.6 \mu \mathrm{m}$ thick. The outer layer was smooth and yellowish-brown in color and $1.3 \mu \mathrm{m}$ thick. The inner layer was light yellow with thickness of $1.2 \mu \mathrm{m}$. One or more polar granules were present. The micropyle measured $1 \mu \mathrm{m}$ wide. The oocyst was identified as Eimeria ninakohlyakimovae. This was in congruence with earlier report of Sharma et al., (2009). Prevalence studies on oocyst affections in goats have suggested that Eimeria ninakohlyakimovae is frequently associated with caprinecoccidiosis and is regarded as the most pathogenic protozoan for goats of all ages (Kanyari, 1993).

The caeca revealed anterior end of Trichuris ovis embedded in the mucosa. The worms isolated from intestinal segments had morphological characteristics of transversally striated cuticle. In males, the posterior end was spirally coiled with a single spicule, having slightly expanded proximal and a pointed distal end. In case of female, posterior extremity was slightly curved. On the basis of morphological features, worms were identified as Trichuris ovis (Soulsby, 1982). Histopathological examination of intestine revealed Eimeria ninakohlyakimovae residing 
in the lower small intestine and large intestinal segments. Developmental stages including microgamonts and macrogamonts infecting the segment of small intestine were observed. Eosinophilic nuclei with centrally placed nucleus in macrogamonts and basophilic nuclei in microgamonts were arranged in periphery with infiltration of lymphocytes and few plasma cells in the infected area (Fig. 1). Hyperplasia of intestinal epithelium and chronic enteritis characterized by infiltration of lymphocytes in enterocytes of intestinal villi were the characteristic pathological lesions (Fig. 2). Villus blunting and necrosis of intestinal villi was observed due to the embedded attenuated anterior end of Trichuris ovis (Fig. 3). The histopathological lesions were in agreement with results of Hashemnia et al., (2012). Overall, it is proposed that the subclinical coccidiosis poses economic losses which might be higher than the ones caused by clinical coccidiosis (Cornelissen et al., 1995). Hence, this study cautions the goat husbandry professionals about the significance of preliminary screening of the samples and consideration about the possibility of the prevalence of mixed infection. This will help in the prompt identification of the disease and ensure early and appropriate management strategies along withan effective therapeutic regime.

On the basis of parasitological and histopathological findings, the case was diagnosed to be a mixed infection of Trichurisovis and Eimeria ninakohlyakimovae in goat. Proper managemental strategy is the need of the hour to curb the growing mishap of parasitic infestation in goats worldwide.

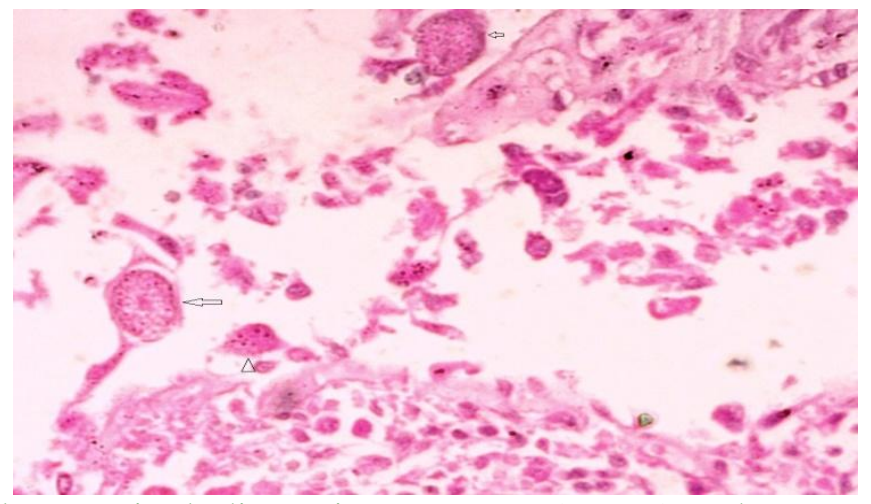

Fig.1 Developmental stages including microgamonts (arrow) and macrogamonts (arrowhead) infecting the segment of small intestine (H \& E, 20X)

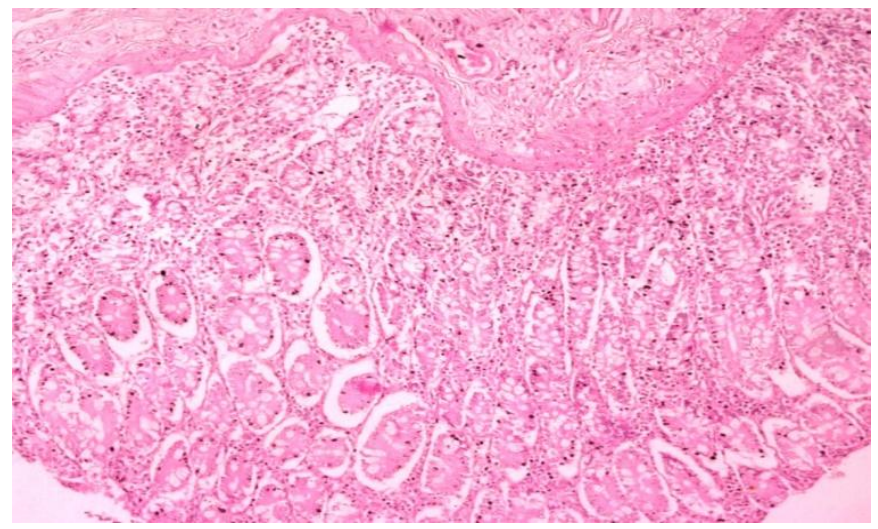

Fig.2 Hyperplasia of intestinal epithelium and infiltration of lymphocytes in between enterocytes of intestinal villi. (H \& E, 20X) 


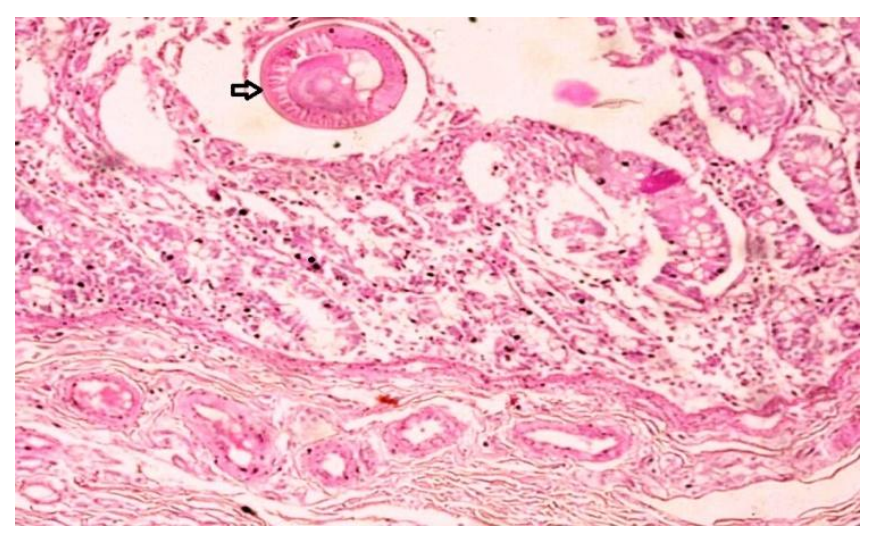

Fig.3 Villus blunting and necrosis of enterocytes at tip of intestinal villi due to the embedded anterior end of Trichuris ovis (arrow). (H \& E, 20X)

\section{Acknowledgement}

We are grateful to the Associate Dean, Nagpur Veterinary College, Maharashtra Animal and Fishery Sciences University, Nagpur

\section{References}

Cornelissen,A. W. C. A., Verstegena, R., Van den Branda H., Periea, N.M., Eyskera, M., Lamb, T. J. G. M and Pijpers, A. 1995. An observational study of Eimeria species in housed cattle on Dutch dairy farms. Veterinary Parasitology 56: 7-16.

Grencis, R. and Laura J. C. 2004. The Trichuris muris system: a paradigm of resistance and susceptibility to intestinal nematode infection. Adv. Parasitol. 57:255-307.

Hashemnia, M., Khodakaram Tafti, A., Razavi, S. M. and Nazifi, S. 2012. Experimental caprine coccidiosis caused by Eimeria arloingi: morphopathologic and electron microscopic studies. Vet. Res.Commun. 36: 47-55.

Kanyari, P. W. N. 1993. The relationship between coccidial and helminth infections in sheep and goats in Kenya. Veterinary Parasitology 51: 137-41

Koudela, B. and Boková, A. 1998.Coccidiosis in goats in the Czech Republic. Veterinary Parasitology76: 261-267.

Luna, L. G. 1968. Manual of histological staining methods of the Armed Forced Institute of Pathology, $3^{\text {rd }}$ ed. McGraw Hill book Co, London, pp. 124-125.

Nourani, H., Karimi, I. and Azizi, H. 2006. Severe and diffuse nodular hyperplasia of jejenum due to Eimeria species in an Iranian native kid. Pakistan Journal of Biological Sciences 9(8): 1584-1586.

Ruiz, A., González, J.F., Rodríguez, E., Martín, S., Hernández, Y. I., Almeida, R. and Molina, J.M. 2006. Influence of climatic and management factors on Eimeria infections in goats from semi-arid zones. Journal of Veterinary Medicine Series 53: 399-402.

Sharma, D. K., Nimisha, A., Ajoy, M., Pooja, N. and Saket.2009. Coccidia and gastrointestinal nematode infections in semi-intensively managed Jakhrana goats of semi-Arid region of India. Tropical and subtropical Agro-ecosystems, 11:135-139.

Soulsby, E.J.L. 1982. In: Helminths, Arthropods and Protozoa of Domesticated Animals $7^{\text {th }}$ Ed. ELBS and Bailliere Tindall, London, pp. 223.

You M. J. 2014. Suppression of Eimeria tenella sporulation by disinfectants. The Korean Journal of Parasitology 52(4): 435-438.

Zainab, T. and Wajihullah, K. 2016. Morphological and histopathological studies of Trichuris ovis in goat intestine. Journal of Parasitic Diseases: Diagnosis and Therapy 1(1): 1-7. 
How to cite this article:

Chelkar, M., S. Panda, M. S. Hedau, N. V. Kurkure and Kolte, S.W. 2020. Concurrent Infection of Trichuris ovis and Eimeria ninakohlyakimovae in Goat: A Case Report. Int.J.Curr.Microbiol.App.Sci. 9(12): 1837-1841. doi: https://doi.org/10.20546/ijcmas.2020.912.218 